\title{
Comprehensive Cancer Center of Wake Forest University
}

National Cancer Institute

\section{Source}

National Cancer Institute. Comprehensive Cancer Center of Wake Forest University. NCI

Thesaurus. Code C39367.

The mission of the Comprehensive Cancer Center of Wake Forest University is to improve the lives of cancer patients by focusing basic, clinical, and population sciences on the problems of cancer prevention, early diagnosis, and novel treatment. The Center has established three Centers of Excellence in brain, breast, and prostate cancer. It became an NCl-designated cancer center in 1974 and a comprehensive center in 1990. 